\title{
"I think it's up to the media to raise awareness." \\ Quality expectations of media coverage of climate change from the audience's perspective
}

\author{
Nina Wicke*, Technische Universität Braunschweig, Institute for Communication Science, Germany \\ Monika Taddicken, Technische Universität Braunschweig, Institute for Communication Science, \\ Germany \\ ${ }^{*}$ Corresponding author: n.wicke@tu-braunschweig.de
}

\begin{abstract}
This study aims to increase the understanding of how the media should report scientific issues by exploring audience's expectations of how the media cover the contemporary, global issue of climate change. Drawing upon qualitative group discussions $(n=26)$ and on the theoretical perspective of Wolling's Theory of Subjective Quality Assessments (TSQA), we provide insights into the relations between public views on climate change and the expectations and assessments of its media coverage. Stimuli material of climate change media coverage presenting uncertainty, a scientific claim, and emotional appeal was integrated. Overall, the relevance of the media for this public issue was emphasized. Despite diverging opinions on how the media should adopt its societal function, a more solution-oriented, detailed and diversified coverage was desired to provide guidance and to overcome topic fatigue. Differing quality dimensions regarding content and reporting style from the audience's perspective were derived.
\end{abstract}

\section{Keywords}

science journalism, quality expectations, assessments, audience perspective, climate change, group discussions, Theory of Subjective Quality Assessments (TSQA)

\section{Introduction}

The media play a relevant role in the dissemination and communication of scientific research and its findings. Usually, citizens receive this information through mediated communication, not through scientific publications or first-hand experiences such as engagement processes (National Science Board, 2018; Newman, Nisbet, \& Nisbet, 2018; Su, Akin, Brossard, Scheufele, \& Xenos, 2015). Thus, the media coverage is of particular importance for the social handling of a scientific topic and often forms the basis for everyday decisions. Therefore, science journalism plays a dominant role. However, it is challenging to report about science as its findings are often highly complex and, at the same time, very abstract. Further, these findings are sometimes uncertain and conflicting and are therefore not easily understood by laypeople. Journalists must consider how to present this scientific abstractness, uncertainty, and contradictoriness while at the same time being guided by journalistic principles, organizational structures, and individual preferences (Dunwoody, 1999; Maier et al., 2016; Stocking \& Holstein, 2009). Moreover, Loosen and Schmidt (2012, p. 873) describe the audience as "a highly important point of reference" for journalists and to consider this when producing content in order to be noticed and to justify its existence. This can be underscored by the finding that dissatisfaction with media coverage reinforces "media frustration" and even a loss of trust (Donsbach, Rentsch, Schielicke, \& Degen, 2009; Newman \& Fletcher, 2017). This is particularly problematic for science journalism, where trustworthiness of content and sources is of particular importance. Moreover, recipients' decisions of selection and 
usage, as well as their issue perception and awareness, are also affected by their needs and demands. It is crucial to know what is actually expected of science journalism. Research on audience's expectations and their evaluations of media's coverage of scientific issues is scarce and fragmented. Previous research has emphasized that understanding the audience is at least as important as analyzing the media and its frame-building (Morton, Rabinovich, Marshall, \& Bretschneider, 2011; O’Neill, 2013; Olausson, 2009; Schäfer \& O’Neill, 2017).

We both address this critical gap and contribute to the analysis of the audience's perspective on media coverage by focusing on the issue of climate change, which is a highly complex, uncertain scientific topic with a high degree of abstraction. The media are one of the key players in creating awareness of climate change, influencing political discourse, and impacting public opinion. Further, as people often derive their knowledge of climate change from the media, their topic-related attitudes, as well as their behavior, are affected by it (e.g., Arlt, Hoppe, \& Wolling, 2011; Bolin \& Hamilton, 2018; Carmichael, Brulle, \& Huxster, 2017; Lowe et al., 2006; Metag, Füchslin, \& Schäfer, 2015; Weingart, Engels, \& Pansegrau, 2000). Previous research has shown that the acceptance of anthropogenic climate change may decrease or increase depending on news media preferences (Bolin \& Hamilton, 2018).

Other than journalistic content, fictional content such as movies like "The Day After Tomorrow", television series, and books have also been shown to be important for people's climate change perceptions and knowledge (e.g., Balmford et al., 2004; Beattie, Sale, \& Mcguire, 2011; Howell, 2011; Lowe et al., 2006; Nolan, 2010). While climate change coverage is a well-researched objective, particularly journalistic content (for an overview, see Schäfer, 2017), how it is perceived and assessed by its audience has received less attention in the research literature.

We remedy this shortcoming by drawing upon four group discussions $(n=26)$ with integrated stimulus material. By considering Wolling's Theory of Subjective
Quality Assessments (TSQA; 2004, 2009), we are able to apply a broad media concept, including news and fictional content. However, science journalism on climate change is the main focus. With this, we aim to both expand the understanding of how science journalism should report about scientific issues such as climate change and to broaden the scholarly discussion in this field.

\section{Quality expectations and assessments of media coverage}

The Theory of Subjective Quality Assessment (TSQA; Wolling, 2004, 2009) is based on the assumption that usage decisions depend on the evaluation of different characteristics of a media product. Wolling's approach postulates that the audience has expectations of quality for certain media product features, which are desirable characteristics, in terms of both content and form, of the media product. The audience can specify what qualities they desire for an ideal product, which can be influenced by their motives. Wolling (2004) has empirically shown that these quality expectations have a significant influence on the media product's level of use. Assessments of these features are the basis for selection behavior. Quality in this approach is understood as "the features of any media product (...) that are significant in the recipient's (...) choosing to give attention to that product" (Wolling, 2009, p. 86). Quality is used in the sense of a descriptive term and is measurable and should not be understood as a normative expression but as a subjective perspective (Wolling, 2004; 2009).

The TSQA states that the perception of these features, and thus the media products' qualities, is an integral part of the reception process. This can be understood as a cognitive process, the result of which is the quality assessment, which is created by comparing the expectations and perceptions of the features. This is then expressed in the act of (not) using a media product (Wolling, 2009). Therefore, the recipients do not primarily evaluate their 
Figure 1: Theory of Subjective Quality Assessment (TSQA)

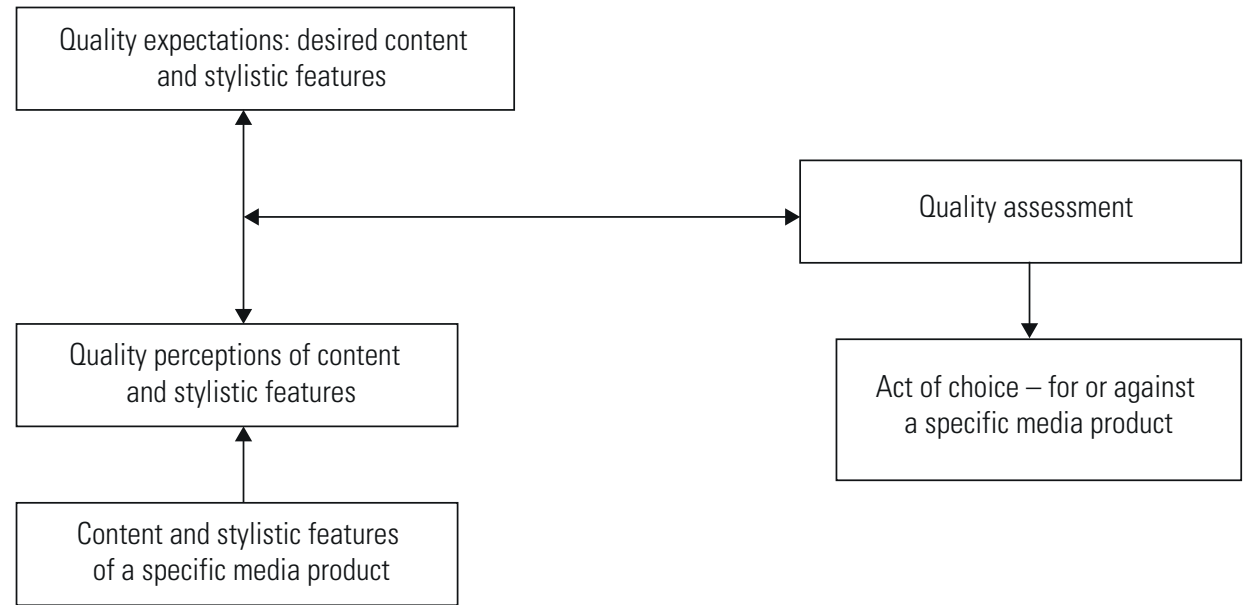

Note: Figure is based on Wolling (2004, p. 175) and Wolling (2009, p. 88)

own behavior, but the media features. Recipients "are more in the position of observers who express an opinion about an external object (the media product) than in that of people who have to judge their own activities [in this case media choices]" (Wolling, 2009, p. 89). If the audience perceives its individual desire regarding specific quality characteristics as fulfilled, it is assumed to assess the media product positively. The same applies to the case that the audience deplores certain features and perceives them as absent. If recipients are disinterested in a particular feature, it is of no significance to their usage choice (Wolling, 2009). However, "deficits in one aspect are not capable of compensation by particularly high performance on the opposing aspect" (Wolling, 2009, p. 93). In summary, the quality of a media product not only depends on its characteristics, but also on the audience's expectations of the ideal format, how they perceive the actual format, as well as how they evaluate and weigh its various characteristics. All of this affects the usage decisions: "The more positive the judgment of quality [...], the more likely the user is to select and regularly use this media format" (Wolling, 2004, p. 174; own translation).
By integrating both a recipient-oriented and a content-oriented perspective, the TSQA (Wolling, 2004, 2009) takes the criticism of the well-known uses and gratifications ( $U \& G$ ) approach into account which is the disregard of specific media content and the insufficient consideration of how the audience processes and understands the media content (Vorderer, 1992). Within the U\& G approach, it remains unclear what the individual gratifications are based on, why and how those gratifications can be obtained, and what has caused the effect (Blumler, 1979). To explain why the audience seeks specific gratifications and respectively specific effects by certain media products, the media content and its attributes should be included. The TSQA addresses this by emphasizing the relevance of "features of the media product". However, this approach has thus far rarely been used. In particular, it remains unclear which features are relevant for the audience when evaluating media. As such, this must be investigated (Wolling, 2009).

In our study, we adopt the TSQA as a framework to explore the relevant features for the audience's perspective on climate change coverage. We follow its premises in order to understand climate change-related media use and media coverage assess- 
ments more deeply. Previous research has shown that the audience has an idea about what constitutes appropriate means for the dissemination of science and scientific findings (Maier et al., 2016; Milde \& Barkela, 2016; Wicke \& Taddicken, 2020). For instance, they expect science journalism to be trustworthy so that it may be relied up and thus to empower them to make their own decisions. Moreover, the audience is interested in background information about research study funding (Milde \& Barkela, 2016). However, studies that considered expectations are scarce, as research has mainly focused on the assessments. For example, national surveys such as the German Science Barometer (Wissenschaft im Dialog, 2020) only evaluate whether the public feels informed about science. Little attention has been paid to quality dimensions from an audience's point of view, and as a result, their examination may also give the media, and particularly journalists, an orientation for effective ways of reporting about science. Therefore, this paper analyzes the following research questions through an explorative study:

[RQ1] What does the audience expect regarding the quality of the media's coverage of climate change?

[RQ2] How is the quality of the media's coverage of climate change assessed by the audience?

The TSQA "operates at a fairly high degree of abstraction” (Wolling, 2009, p. 93). This allows for a wide application field. The audience decides between different media and between different media products. To research their usage decision on these different levels, the explanatory approach can be helpful. We perceive this as an additional value of the theory, due to our assumption that desires also depend on specific media formats and their content, i. e., the audience's quality expectations may differ depending on the mode of presentation such as a documentary report, television news clip, or newspaper article. These expectations also depend on the kind of content, for example fiction versus non-fic- tion as movies versus news. Accordingly, it enables us to consider different media genres and products, and therefore different ways of depicting science and scientific findings. To specify our research aims in this regard, we briefly outline how climate change is presented by the media.

\section{The media coverage of climate change}

Many communication science scholars have researched media coverage of climate change. Most often, the content analyses focus on selected topics as well as on how science journalists present climate change findings (e.g., Barkemeyer et al., 2017; Brüggemann \& Engesser, 2017; Nisbet et al., 2017; Olausson, 2009; Schäfer, 2017). Because of this research, it is known that the amount of climate change coverage has increased in recent years, especially due to the Fridays for Future movement (Sommer, Rucht, Haunss, \& Zajak, 2019) and in the context of events such as the Global Climate Conferences (Schäfer, 2017; Schmidt, Ivanova, \& Schäfer, 2013). The news related to those conferences was found to predict serious consequences of climate change for humanity with little indication to the uncertainty of scientific findings (Ashe, 2013; O'Neill, Williams, Kurz, Wiersma, \& Boykoff, 2015; Painter, 2014). Skeptical frames within the German media's news reporting are rather rare (Kaiser \& Rhomberg, 2016). In general, scientific issues are often portrayed as more certain than they actually are, which is also true for Germany, where this study took place (Guenther, Bischoff, Löwe, Marzinkowski, \& Voigt, 2017). German journalists generally emphasize the evidence of scientific findings, such as highlighting the certainty of a future increase in global temperatures (Maurer, 2011). However, communicating possible effects of climate change inevitably also involves communicating uncertainties, as they go hand in hand with forecasts, for example. This communication affects the audience's perception of scientific authority, especially that of scientists' competence 
and trustworthiness (Jensen, 2008; Johnson, 2003; Morton et al., 2011; Retzbach \& Maier, 2015; Visschers, 2018; Wiedemann \& Schütz, 2008). Furthermore, it has been shown that mentioning scientific uncertainties can raise skepticism about climate change and can lead to confusion and anger in recipients. This in turn can undermine their willingness to mitigate climate change (Corner, Whitmarsh, \& Xenias, 2012; Ding, Maibach, Zhao, Roser-Renouf, \& Leiserowitz, 2011; Rabinovich \& Morton, 2012). Therefore, the manner in which scientific uncertainty is presented is highly relevant for public perceptions of science issues such as climate change. Previous research on the audience's expectations of media coverage on uncertainty is inconsistent. For example, some prefer to be informed about the current state of research, including uncertainties, while others explicitly do not want to be informed about uncertain research findings because they regard this lack of definitiveness as a sign of an incomplete research process (Maier et al., 2016; Milde \& Barkela, 2016). We explore this more deeply in our study:

[RQ2a] How does the audience assess the quality of climate change coverage by the media regarding the portrayal of uncertainty?

Aside from the aspects of uncertainty, media coverage of scientific issues often has a strong scientific character with a focus on scientific experts' statements (Summ \& Volpers, 2016). Scientists usually provide background information and knowledge (Albæk, 2011). Thereby, they often use jargon, inter alia to demonstrate expertise (Bullock, Colón Amill, Shulman, \& Dixon, 2019). Summ and Volpers (2016) examined the current state of science coverage in German print media and showed that the majority of articles about science are fact-oriented and written in a neutral reporting style. Journalistic content is found to frequently focus on scientific arguments such as those in the IPCC report and to be climate change consensus-oriented (Engesser \& Brüggemann, 2016; Peters \& Heinrichs, 2008; Summ \& Volpers,
2016). However, science journalism is often accused of using dramatization and sensationalism (Summ \& Volpers, 2016). Fear appeals, or messages that emphasize the severity and salience of threats, have been found to be common in the climate change coverage (Feldman, Hart, \& Milosevic, 2017; Hart \& Feldman, 2014); for instance, extreme weather phenomena such as storms and melting of the ice sheets (Peters \& Heinrichs, 2008). Ubiquitous images of floods and polar bears, some of the most typical pictures associated with global warming, depict threats to humans (Metag, Schäfer, Füchslin, Barsuhn, \& Kleinen-von Königslöw, 2016; O'Neill \& Nicholson-Cole, 2009). As a result, the media are accused of exaggerating scientific claims for the sake of the story (Weingart et al., 2000). Olausson (2011) confirmed this through group discussions where she found that most recipients criticized sensational forms of climate change reporting. Participants in Ryghaug, Sørensen, and Naess's (2010) study similarly stated that they are fed up by what they perceived as sensation-making media coverage. However, the reception of such media coverage - that said to dramatize climate change - can lead to greater problem awareness (Taddicken, 2013), although this does not have a long-lasting effect and simultaneously reduces the belief in the likelihood of extreme events as a result of climate change (Lowe et al., 2006). Moreover, while using fearful representations of climate change can attract people's attention to climate change, it contributes to public disengagement (Lidskog, Berg, Gustafsson, \& Löfmarck, 2020; O’Neill \& Nicholson-Cole, 2009). To avoid such outcomes, the use of humor and satire can help the audience manage feelings of fear, helplessness, and guilt (Pinto \& Riesch, 2017) and in general, has the potential to make science more appealing, accessible, and may promote reflection on climate change issues, information gathering, and positive engagement (Bore \& Reid, 2014; O'Neill \& Nicholson-Cole, 2009). With this in mind, it is imperative to strike a balance between humor and seriousness. Although the audience may appreciate humorous, 
satirical elements as a pleasant contrast to the serious scientific information, the associated textual ambiguity opens up certain space for interpretation and may lack a clear message about climate change, undermining the impact and credibility of climate change research (Bore \& Reid, 2014; Pinto \& Riesch, 2017). In addition, important issues could be perceived as simplified and trivialized, even more so as a certain level of knowledge about climate change is needed in order to understand related jokes (Riesch, 2015).

Whether forms of emotionalization, i.e., the use of satire, are appropriate means of communicating information on climate change has not yet been extensively researched (Lidskog et al., 2020). We thus explore how the perception of such media content meets and affects the audience's expectations and interpretations, particularly in contrast to a neutral, "scientific" reporting style:

[RQ2b] How does the audience assess the quality of climate change coverage by the media regarding a scientific claim on an issue?

[RQ2c] How does the audience assess the quality of climate change coverage by the media regarding the emotionalization of it?

\section{Method}

To investigate these research questions, four group discussions $(\mathrm{n}=26)$ were conducted. Wolling (2009, p. 94) himself suggested choosing a qualitative method to "discover which elements and aspects they [individuals] talk about to other people when discussing the relevant media product". It is assumed that those are the dimensions individuals base their selection and evaluation of the media product upon. Moreover, the method group discussion was chosen because the increased social interaction, as compared to individual interviews, serves to stimulate thought processes and reflections (Cyr, 2016; Morgan, 1997; Vogl, 2019). This is significant here as reflecting and verbalizing their desires and expectations is typically challenging for participants, particularly regarding science issues. We wanted to explore how climate change reporting is processed by the audience and how understandings of the issue are constructed (i.e., what they thought and why they thought about climate change and its coverage as they did.)

\subsection{Recruiting and participants}

The discussions each had six to seven participants, aged 21 to 69 . We decided that smaller groups would be more suitable for the rather complex topic and that this group size would enable participants to have enough time to voice their views and provide detailed information. The 26 German-speaking participants (11 men and 15 women) were recruited via different avenues, including local newspapers and online forums in Hamburg (Germany). As an incentive, all participants received $€ 30$. A brief standardized screening questionnaire was used to ensure, among other things, sociodemographic heterogeneity, and to construct the discussion groups. For this, we asked about climate change related media use, interest in the topic, problem awareness, and knowledge. Overall, only individuals with at least a minimum level of interest in climate change participated. There were four groups; the

Table 1: Overview of the sample

\begin{tabular}{|c|c|}
\hline \multicolumn{2}{|l|}{ Gender } \\
\hline female & $58 \%$ \\
\hline male & $42 \%$ \\
\hline Age & $\begin{array}{r}M=44.2 \\
(S D=14.5)\end{array}$ \\
\hline \multicolumn{2}{|l|}{ Education } \\
\hline certificate of secondary education ${ }^{\mathrm{a}}$ & $27 \%$ \\
\hline higher education entrance certification ${ }^{\mathrm{b}}$ & $69 \%$ \\
\hline other & $4 \%$ \\
\hline $\begin{array}{l}\text { Climate change related media usage } \\
(1=\text { "never" to } 6=\text { "daily" })\end{array}$ & $\begin{array}{r}M=2.1 \\
(S D=1.2)\end{array}$ \\
\hline $\begin{array}{l}\text { Interest in climate change }(1=\text { "do not } \\
\text { agree at all" to } 5=\text { "strongly agree") }\end{array}$ & $\begin{array}{r}M=4.2 \\
(S D=1.0)\end{array}$ \\
\hline $\begin{array}{l}\text { Knowledge of climate change } \\
\text { (Index 1-13, the more the higher) }\end{array}$ & $\begin{array}{r}M=7.3 \\
(S D=2.9)\end{array}$ \\
\hline $\begin{array}{l}\text { Problem awareness }(1=\text { "do not agree } \\
\text { at all" to } 5=\text { "strongly agree") }\end{array}$ & $\begin{array}{r}M=1.4 \\
(S D=0.5)\end{array}$ \\
\hline
\end{tabular}

Note: $\mathrm{n}=26$. a) Haupt- $/$ Volksschulabschluss and Mittlere Reife/ Realschulabschluss. b) Fachhochschulreife and Abitur. 
first of which was highly educated, in their twenties, and possessed middle to high knowledge about basic climate change facts. The second group was still highly educated, but to a lesser degree. They were middle-aged, with a low level of climate change knowledge. The third group was composed of participants with the highest knowledge level, were middle-aged (although on average slightly younger than the second group). The fourth group was the most heterogeneous regarding age with participants in their twenties, forties, and fifties, all of which had a medium level of knowledge.

\subsection{Discussions and conversation guidelines}

The discussions lasted between 90 to 120 minutes and were led by one of the authors with experience in qualitative interviewing. Her role was to manage the discussion, to ask follow up questions for elaboration on interesting points, and to encourage engagement among participants (Kühn \& Koschel, 2011). She relied on conversation guidelines (see Online Supplement A) to structure the discussions and to ensure that all relevant topics regarding the study's research interests were considered (Helfferich, 2011; Kühn \& Koschel, 2011). The guidelines had been discussed beforehand among the whole research group to ensure quality control. The first group discussion was conducted as a pretest to observe the time length of the discussion and whether or not the participants become weary. Moreover, the pretest aimed to ensure whether the guidelines were functional and that there were no difficulties in understanding the questions (Hurst et al., 2015; Lindlof \& Taylor, 2019). As this was the case, this discussion was also included in the analysis.

The research team created a friendly and welcoming atmosphere before and during the discussions. After a joint round of introductions, most of the participants took part in the discussion on their own accord. In the beginning of the sessions, the participants' attitudes toward climate change as well as their media usage were discussed. Following this, the participants were invited to explain how they perceive and assess the media coverage of climate change, such as its adequacy, extent, and credibility. Questions were then introduced to stimulate discussion on typical reports about climate change in the German mass media and, in order to ascertain their expectations, what an ideal report would be like. All groups debated in a committed and intensive manner, to the extent that many questions in the conversation guide were covered through the natural flow of conversation. The participants used their personal experience and specific media usage occasions to explain their reasoning. As such, intervention was minimal aside from a few instances where participants were either not participating or were not giving others opportunity to speak.

\subsection{Stimulus material}

After around 45 to 60 minutes of conversation, participants were shown three audiovisual excerpts from German public broadcasters representing different forms of climate change coverage (see Online Supplement B). We focused on television as it is still the medium by which the majority of Germany's population obtains information about science and technology (Wissenschaft im Dialog, 2018). The stimuli consisted of three videos and each lasted around 90 seconds. These were used in order to further the discussion about the style of media coverage and expectations of the audience regarding the presented level of (a) uncertainty, (b) "scientific" claim, and (c) emotional appeal. The first stimulus was a news broadcast showing two scientific experts - a wellknown climate scientist and a geophysicist - who advocated contrarily about climate developments. This video addressed the uncertainty and contradictoriness of climate science findings. The second stimulus, a documentary report, featured an oceanographer who explained the results of his climate change research and the applied scientific method behind it in detail. A third television excerpt portrayed climate change from a satirical, humorous and entertaining perspective 
where possible negative implications of climate change, such as global warming, were highly exaggerated and portrayed as positive developments. The message was critical of the often sensationalistic and dramatizing way of reporting.

\subsection{Saturation}

The guiding principle for sample size and data collection was the concept of saturation (Charmaz, 2014; Mason, 2010; Moser \& Korstjens, 2018; Nelson, 2017; O’Reilly \& Parker, 2013; Saunders et al., 2018). Charmaz (2014) proposes defining saturation by robust, rich categories which have conceptual depth, showing the patterns, categories, and variety of the phenomenon under study (Moser \& Korstjens, 2018). The study's aim was to achieve richness and depth of analysis, and thus to extend and advance knowledge. Elements of both theoretical and data saturation were combined (Saunders et al., 2018). Saturation was reached when we had the impression that no new analytical information had arisen (Moser \& Korstjens, 2018). New perspectives about the participants' media usage, their perceptions of climate change coverage and ideas on how climate change should be reported could not be gathered, but a sufficient depth of understanding was reached to allow for theorizing (Nelson, 2017). To be sure of this, the final group was made to be more heterogeneous than the previous ones so as to capture additional aspects through possible differing opinions, experiences, and perspectives.

\subsection{Transcription and content analysis}

Group discussions were audio recorded and later transcribed with the software "f4transkript" based on a set of transcription rules by Kuckartz (2018) and Dresing and Pehl (2015) which focus on the content. Transcripts were analyzed thematically according to our research questions (Mayring, 2014). We immersed ourselves in the data by reading and rereading the transcripts carefully and conscientiously, in search of deeper understanding (Moser \& Korstjens, 2018). We applied an iterative approach to analyze the group discussions and, based on theoretical considerations and following our conversation guidelines, predefined a coding scheme. The analysis focused on exploring and identifying quality expectations and assessments regarding the content and style of climate change coverage. Based on the actual data, we developed additional categories. Within this process, we went through the data and examined what emerged from it. In accordance to Mayring (e.g., Mayring, 2014; Mayring \& Fenzl, 2019), we used both structuring and summarizing content analyses, thus combining a deductive and an inductive approach. We defined categories and created coding rules and added anchor examples. The coding scheme (see Online Supplement C) was applied using the software "MAXQDA" for the coding process. We used this to structure and organize the data and to classify and annotate relevant text passages. For quality control of the coding process, we applied a consensual coding method (e.g., Kuckartz, 2018) to improve the reliability of the codings. The iterative coding process was conducted by the authors, supported by another senior researcher. Using the same coding scheme, the results of the analysis were compared to determine whether coders agreed on the coded content. Early in the process, differences were discussed and a common understanding of the coding scheme was developed to ensure consistency. Following the analysis, selected quotations from the group discussions were translated to English by the authors and proofread by a native English speaker. Those presented in the following results section function as illustrations and typical examples from the coded empirical data.

\section{Results}

The findings of our study reveal a range of "media features" (Wolling, 2009) individuals take into account when evaluating the media with regard to climate change. We differentiate between the expectations [RQ1] and assessments [RQ2; RQ2a-c] and 
assign the media features to content and style to allow for greater clarity.

All participants indicated they were interested in climate change and that the media are their main source of information. They mentioned that they do not actively search for information about climate change, but come across such content in their usual media consumption. They relied especially on content reported in newspapers and on television. Other people, such as family and friends, were not mentioned as sources.

\subsection{Quality expectations of media coverage of climate change [RQ1]}

We first explored the audiences' quality expectations of the media with regard to climate change. For this, we focused on the media's coverage of climate change and analyzed "the ideal coverage", while naturally allowing statements on the media in general. Overall, the participants expected the media to provide high quality, detailed, comprehensible, and accurate information about climate change. Acknowledging the "gate-keeping" role, the journalists were expected to select relevant science information and to structure it in their reporting. Participants in the study were aware of differences between media channels, as they, for example, assessed radio as an "incidental" medium, which was considered unsuitable by some of them for communicating complex topics such as climate change. Although all participants often argued using the term "the media", it eventually became clear that, on occasion, that they had journalism in mind when saying this. Furthermore, other media content, such as movies, series, and novels, were explicitly mentioned throughout the discussions. In the following, we attempt to differentiate between the media and journalism or other content where possible, but it is important to be aware that the different contents seem to merge for the participants.

\section{A) Quality expectations on content}

A typical first response to the question asking what participants' ideal coverage would be like was that the media should report constantly on climate change more broadly. Participants indicated that they expect the media to generate and maintain attention for the topic: "I think it's up to the media to raise awareness." (GD3, M32). ${ }^{1}$ Participants emphasized the agenda-setting function of the media. They assigned a high normative relevance to the media in general. Thus, they problematized the economic constraints and profit orientation that the media, here mainly journalism, underlies which was particularly seen as negative for complex and unpopular topics such as climate change. Among the suggestions made by participants for improvement were that unappealing television broadcasting times be changed to prime time, for example immediately following the news, and that there should be theme days and special formats for children.

The shared expectation of providing high quality climate change information was discussed in greater detail. The participants do not want to have to check or reinvestigate the content published, but do want to be able to trust it. Overall, they desired more scientific facts on the issue. This was understood to be background information on scientific methods and findings. For instance, transparency aspects of scientific research - and thus information on its trustworthiness - should be presented clearly. In particular, donors and the source of a study's funding are of interest to some participants:

I am interested in more information about "behind the scenes", so to speak, about climate change. [...] What role does it play if a company somehow funds these investigations or these research programs? I do not know anything about these processes. (GD1, F31)

Furthermore, participants hoped for more information on the effects of climate change, not just its causes. A lack of contextualizing was highlighted, such as global contexts and consequences of climate

1 To retrace quotations, participants were labelled with a personal ID (Gender/Age). 
change, to offer the audience a higher level of orientation and knowledge. Nearly all participants believed that human beings are responsible for causing climate change. Interestingly, they questioned the political efforts against climate change and strongly emphasized the individual's responsibility to act. Consequently, the participants felt that the presentation of behavioral options at the individual's level was lacking in the media coverage. Some participants clearly called for journalism to provide the population with explicit recommendations for climate friendly action and to increase the problem awareness among the public. In their eyes, educationally effective journalism is necessary in order to evoke and foster reflections on the consequences of climate change, particularly those caused by humans. Although this was not denied, some, however, felt uncomfortable with this: "The task of the media is not to spread opinions" (GD3, M50).

\section{B) Quality expectations on style}

Overall, the participants perceived the media, journalists in particular, as "science translators" and required a high level of comprehensiveness. For instance, journalistic presentations should be scientifically well founded, but also generally easy to understand. Visualizations of climate change can be helpful for this. The reception of media content on climate change should not be too time-consuming, but rather reported "briefly and concisely" as news content which is too extensive might overly strain the audience, causing fatigue and leading them to tune out: "When I look at ZEIT [German weekly quality newspaper], there are five pages about climate change and at some point I stop reading, because it becomes too much for me" (GD2, M67). According to the participants, the ideal reporting style is optimistic or at least oriented to what can be done, and somehow constructive. One participant suggested featuring individuals in the media who combat climate change as they could serve as role models for the audience. Journalistic content should be more measures-oriented and informative as to what individ- uals can do for the mitigation or adaption of climate change:

I would ask for a report [...], [about] what we can do as individuals, because political solutions such as the Kyoto Protocol etc. do not make a difference [...]. What is really important is what every individual can do. This could be taught [by the media]. With examples from all over the world, how others try to fight [climate change]. (GD2, F44)

Moreover, the media coverage should have a higher news and entertainment value in order to overcome topic fatigue which was also related to uninteresting media content. Although a neutral and objective style of reporting was found to be necessary, the German media's coverage was criticized for being too "uniform": participants expected varied and multifaceted journalistic content on climate change. Some suggested presenting it in an entertaining and humorous manner, so that a larger and more diverse audience can be reached.

Table 2: Quality expectations of the ideal climate change coverage

\begin{tabular}{l|l}
\hline A) Content & - high information level \\
& - trustworthiness of information \\
& - communication of scientific facts and scientific \\
& research processes \\
- contextualization of effects of climate change & - educational role \\
B) Style & - comprehensible \\
& - too time-consuming \\
& - measures-oriented, constructive \\
& - varied, multifaceted \\
& - entertaining \\
\hline
\end{tabular}

In general, the participants seem to have set high standards. Some of the quality expectations of ideal media coverage are partly contradictory and difficult to fulfill. For instance, most of the participants would like journalists to report in a neutral and balanced way, while at the same time expecting the media to help them form their own opinion and give clear advice on how to mitigate climate change. Participants called for an increase in the quality of information, which includes the con- 
textualization of climate change research but indicated that the content should be not too extensive. These rather conflicting, irreconcilable expectations can be placed on an "arc of suspense" (Vowe \& Wolling, 2004 , p. 17). Therefore, high quality is probably not achieved by increasing certain features of a program more and more, but probably corresponds to an ideal point on the arc of suspense where the mutually opposed demands meet best in combination (Wolling, 2009).

\subsection{Assessments of media coverage of climate change [RQ2]}

The participants discussed not only how media coverage should be (idealistic) but also how it is and what they think about it (realistic). In this context, the participants did not talk much about the actual media coverage, but rather what kind of content they feel is lacking. The participants agreed that there is overall too little reporting on climate change.

\section{A) Assessments of content}

Several of the participants criticized the media for reporting in a superficial way and considered the information level to be low. Generally, climate change was seen to be covered mainly in documentaries and reportage. The presented content was found to be homogenous. Certain statements and topics such as the forecasted global temperature rise were seen as overly repetitive. Some participants suspected different media outlets of using the same sources or copying and adapting content from each other.

\section{B) Assessments of style}

The media's coverage of climate change was assessed as being negative, emotional, and particularly sensationalistic. Further, the participants agreed strongly that climate change seems to be frequently reported in the form of dramatic events such as (natural) disasters, when "there are as many dead people as possible to lament" (GD3, F53) and shocking images, such as at least in Germany - the ubiquitous polar bear on a melting ice floe and desert-like landscapes, which can be used to attract attention, at least in the short term. This has led to a certain level of frustration and a reduction in participants' interest in climate change:

I also think that with this subject in particular, somehow, [...] there seems to be a need to sensationalize everything. There is no frame in which it can otherwise be done; it always must be linked to some dramatic event, and I think that the issue is beginning to wear out, that one gets fed up with this never-ending sensationalist reporting on this issue. (GD1, M27)

Table 3: Assessments of climate change coverage with regard to the audience's expectations

\begin{tabular}{l|l}
\hline A) Content & $\begin{array}{l}\text { - information level: low, no content diversity } \\
\text { - trustworthiness of information: one-sided, } \\
\\
\text { copied content }\end{array}$ \\
B) Style & $\begin{array}{l}\text { measures-oriented, constructive: sensational- } \\
\text { ized, negative } \\
\text { - varied, multifaceted: stereotypical visualization }\end{array}$ \\
\hline
\end{tabular}

The TSQA (Wolling, 2009) states that quality assessments are composed of a comparison of individuals' expectations and their perceptions of the media features. Comparing the media features the participants discussed while describing their ideal media coverage of climate change and the media features they considered for assessing it, it becomes clear that they are related to each other. For example, as participants expected media content with "high information levels", they criticized what they perceived as "low information level". They want the media to report in a varied and multifaceted way and are unsatisfied with what they perceived as stereotypical visualizations. In addition, the participants focused mainly on the negative and missing aspects of media coverage. Apart from the criticism, the participants believed that reporting on climate change is a thankless task given its multidimensionality, abstraction, and complexity. Some considered it to be also a visual challenge as few aspects of climate change could be displayed graphically. This indicates that participants consider their own 
expectations to be difficult to meet. Moreover, it was acknowledged that journalists themselves are rarely scientific experts in the field: "Overall, I don't find it that bad what the media are doing" (GD1, M27). A further discussion on the extent to which journalists are actually either able or required to fulfill the ideas of the audience is needed.

\subsection{Assessments of three different forms of climate change media coverage [RQ2a-c]}

To explore how the participants assessed the media coverage of climate change, three audiovisual excerpts from German public broadcasters were shown which represent the uncertainty of scientific findings, the "scientific" claim of the issue, and the sensationalized emotional appeals.

\subsubsection{Uncertainty of scientific findings [RQ2a]}

Opinions were divided across the group discussions regarding the communication of uncertainty and differing scientific perspectives. Some participants actually liked this kind of content and said a clear statement by the media was unnecessary as they perceived it their own responsibility to form an opinion. However, the majority of the participants felt uncomfortable. While most of them assessed the content as being scientifically correct, they agreed that the differing perspectives increased the challenge of forming one's own opinion. This reinforced the perceived complexity of the topic and contributed to a sense of uncertainty in the participants, who also expressed that they do not know how they should utilize this information or which scientist they should trust. According to the participants, this is also due to the fact that they themselves lack knowledge and that the television excerpt presented no scientific methodology when explaining the results and arguments. Therefore, their evaluation of the expert's credibility and expertise is not based on their statements or on the perceived scientific nature, but instead, as one participant explained, on "absurd" (GD1, M27) criteria such as attractiveness, clothing, and self-presentation of the experts. Further, in this context the participants discussed the expert's motives and questioned who might be funding their research. In their opinion, science must be independent. For some participants it seemed that scientists are not working together, but rather against each other which was assessed as being negative. Participants even had the impression that one of the two experts was untruthful: "One of the two must be lying" (GD2, M67), which created a feeling of anger and disillusionment.

Moreover, they were concerned that reporting uncertainties could possibly weaken the threatening character of climate change and its possible consequences and some, indeed, reported that the stimulus had reduced their fears and raised doubts regarding the seriousness of the situation. This was perceived as "dangerous" by other participants who were concerned that media content highlighting the uncertainty of scientific findings could convince laypeople that humankind is not responsible for climate change and thus do not actively engage against climate change. However, some were of the opinion that the balanced nature could foster information-seeking behavior:

\footnotetext{
There is no one who can do your thinking for you, no media. I must draw on as much media as possible, and when this television broadcast is not enough to enable me to form an opinion, then I need to read up and look up on the internet what kind of expert he is and what he investigated. In other words, to inform myself. (GD3, F53)
}

\subsection{2 "Scientific" claim [RQ2b]}

The second television excerpt consisted of an oceanographer explaining a specific scientific method and the results found with it. The participants described this stimulus as "very scholarly", scientifically sound and objective, which they assessed as being positive. The scientist was perceived as comprehensible and trustworthy. Participants indicated this is also due to the fact that the scientist explained the scientific method. Therefore, the results 
also appeared valid. Whether the explanation of the method was actually necessary or whether a presentation of the results would have sufficed, led to disagreement among the group discussions participants. One participant explained that "For me, this information [about the method] is of no use, because I can't comprehend it" (GD1, F25). They also discussed whether the stimulus is too closely oriented to a specialist audience, as many technical terms and scientific jargon were used, and laypeople might find it difficult to understand the topic. Thus, the language used seems to be part of the perceived media features as well.

Some participants lamented that there was no contextualization of the scientific discoveries. For the audience, it remained unclear what its causes were and what the consequences for human beings would be, and in their opinion, a conclusion or the recommendation for action derived from the findings is particularly relevant.

Moreover, the participants assessed this form of media coverage as boring even though they acknowledged that at least an attempt was made to make it entertaining by stylistic features such as ambient music, for example.

\subsubsection{Emotional appeal [RQ2c]}

The third television excerpt presented climate change in a highly emotional, but satirical way: Potential negative consequences of climate change were visibly over-exaggerated and depicted as positive developments. This was assessed as being controversial as well.

This media stimulus was positively perceived as humorous and different to the usual reporting of climate change. Participants believed that, through such entertaining formats, the interest in climate change could be (re)awakened and also expanded to reach those audiences who have so far been less concerned with climate change. Moreover, some participants thought that - due to the exaggerated nature of the representation - the content might be more easily remembered and that reflection on the effects of climate change could be fostered. Other partici- pants suspected this obvious exaggeration might lead to a failure in recognizing the problematic nature of climate change, and thus, to a certain degree of "diminution" (GD2, M67). Some thought that this satirical way of reporting is inappropriate as the topic is too serious and socially relevant. Parts of the groups also perceived this mode of presentation as difficult and demanding because the content is not communicated clearly and unambiguously. This does not only require knowledge about climate change, but also about the medium or format in order to understand the content correctly.

Table 4: Assessments of three different TV stimuli on climate change and the media features taken into account

\begin{tabular}{|c|c|}
\hline $\begin{array}{l}\text { 1) Uncertainty } \\
\text { of findings }\end{array}$ & $\begin{array}{l}\text {, communication of scientific facts and } \\
\text { scientific research processes: } \\
\text { + scientifically correct } \\
\text {, high information level: } \\
\text { - reinforces the complexity of climate change } \\
\text { - increases the challenge of forming one's } \\
\text { own opinion } \\
\text { + fosters information-seeking }\end{array}$ \\
\hline $\begin{array}{l}\text { 2) "Scientific" } \\
\text { claim }\end{array}$ & $\begin{array}{l}\text {, trustworthiness of information: } \\
\text { + very scientific and trustworthy } \\
\text { contextualization: } \\
\text { - lack of causes and effects } \\
\text { comprehensibility: } \\
\text { - difficult to understand due to the mea- } \\
\text { surement method and the use of scientific } \\
\text { jargon }\end{array}$ \\
\hline $\begin{array}{l}\text { 3) Emotional } \\
\text { appeal }\end{array}$ & $\begin{array}{l}\text { varied, multifaceted, entertaining: } \\
\text { + interest in climate change could be } \\
\text { (re-lawakened } \\
\text { + reaching different audiences } \\
\text { - underestimating relevance of climate } \\
\text { change } \\
\text { - inappropriate due to the topic's seriousness } \\
\text { comprehensibility: } \\
\text { - requires knowledge about the issue and } \\
\text { the medium or format }\end{array}$ \\
\hline
\end{tabular}

Overall, the participants described the media as an important source of information from which to form an opinion about climate change. All participants considered themselves to be laypeople, with regard to climate change science, and perceived themselves as being dependent on what and how the media report about climate change: "That is why I also find 
it very hard [...] to form a firm opinion, since I ultimately rely on research results which I read in the newspaper" (GD1, F25). Hence, apparently the media play a relevant role in informing the audience about climate change and are perceived as quite important.

\subsection{Quality dimensions of the media coverage}

Based on both the expectations of, and assessments by the participants, and the related media features, different basic quality dimensions for the media coverage of climate change can be derived. These dimensions can be transferred to the communication of science and scientific issues and are outlined in the following descriptions:

(1) The media were expected to raise awareness and to generate a broad reach for the scientific issue. It was particularly important to the participants that scientific content, which is often highly abstract, complex, and therefore difficult to understand, is explained in a comprehensible way. The use of technical terms and scientific jargon was seen as an obstructive barrier for comprehensibility. They expected the media to contextualize scientific findings so as to provide them with a greater level of orientation. (2) Additionally, the audience is usually unfamiliar with scientific research processes and methods. The participants wanted a better explanation of how science actually works in order to increase their understanding, but at a low level. (3) This could also help them to deal with the uncertainty and contradictoriness of scientific findings. The participants made clear that it is difficult to form one's own opinion regarding scientific issues such as climate change as they consider themselves to be laypeople and thus as not able to judge the quality of scientific research. Therefore, it is a substantial challenge for the media to expose their audience to uncertain scientific findings without increasing distrust. (4) In line with this, the audience may take into account another dimension when evaluating the media coverage: The participants had the impression that the media are overly re- petitive with the same information. The presentation of the diversity of (scientific) perspectives and findings, to show which disciplines are involved in researching the topic, for example, could raise transparency and trust. (5) Furthermore, related to the abstractness and complexity of climate change, it was difficult for the participants to recognize and understand the importance of the topic for their own lives. They stated several times that they would like the media to recommend implementable behaviors for their own lives which can mitigate climate change. Therefore, the everyday relevance of the scientific issue which illustrates the "practical application" of the scientific findings could be pointed out. (6) With regard to reporting style, the participants desired a certain news and entertainment value, including emotional appeals, though to a reasonable extent, and to be optimistic and encouraging, as well as high quality and trustworthy.

Table 5: Quality dimensions of science communication

\footnotetext{
(1) Comprehensibility of complex scientific issues

(2) Explanation of scientific research processes and methods

(3) Pointing of the uncertainty and contradictoriness of scientific findings

(4) Presentation of the diversity of (scientific) perspectives

(5) Highlighting of the everyday relevance of the scientific issue

(6) Consideration of a certain news and entertainment value
}

\section{Discussion and conclusion}

This study contributes to the empirical analysis of the perceived quality of media by exploring the expectations of, and assessments by the audience. The aim of this paper is to describe relevant media features and dimensions for the communication of the scientific issues that matter for audiences. This is important because their expectations assumingly affect assessments and thus selection and usage decisions that in turn influence issue perception and awareness of individuals. We applied an all-encompassing approach of "the media" to include non-journalistic 
media content as it has been shown to be important (e.g., Balmford et al., 2004; Beattie et al., 2011; Howell, 2011; Lowe et al., 2006; Nolan, 2010).

In order to better understand the audience's media perceptions, we applied the idea of differentiating quality evaluations in expectations and assessments (Vowe \& Wolling, 2004; Wolling, 2004, 2009). For this, we chose the qualitative approach of group discussions that proved to be beneficial. We integrated different reporting styles by presenting three short audiovisual excerpts from German public broadcasters.

The analysis of the participants' contributions revealed a basic and general common ground on the media's role in general as well as some divergent and contradictory opinions. The relevance of the media for disseminating information about this issue was generally accepted and its authority well-acknowledged. Further, its agenda-setting function and societal relevance was highlighted. The participants saw the media as responsible for keeping this important topic on the agenda. They disagreed on whether the media should provide neutral and balanced information, or play a guiding role by helping individuals to form their opinion and provide clear recommendations for individual climate friendly action. Here, the extreme positions of "the media as information broker" and "the media as opinion-maker" were both enunciated.

Even though the participants often talked about the media in general, they recognized the differences between different media channels and formats. For instance, they considered the economic constraints which influence program structures, and they determined that different media formats enable different forms of representation, and thus how various media can present the issue. In other words, the variety of content in the heterogeneous media landscape is acknowledged and welcomed. This also underscores the idea of the TSQA taking media product characteristics into account.

However, the media coverage was overall only assessed as being of little in- formative value and uncreative. Further, the repetitive manner in which the information was given was criticized. Other information which was expected from the media, such as issue backgrounds, scientific processes, and contexts, were exceedingly felt to be lacking. From this study, it remains unclear whether the quality of science-based information is indeed as low as perceived by the participants. But it has indeed been found that the occurrence of science-centric frames in media coverage of climate change has decreased over time, whereas socio-political frames have increased (Kirilenko \& Stepchenkova, 2012).

The underlying tenor of the media coverage was important for the participants as well. They believed the issue to be permanently sensationalized. The media coverage was overall seen by participants as threat-and-risk-oriented, though, they desired a constructive style of reporting by presenting actionable options for individuals, although this might be at the adapting level. The mutual character of expectations and assessments (Wolling, 2004,2009 ) is important here as the assessment of a sensationalized, predominantly negative style of reporting interacts with the unfulfilled expectation of a more solution-oriented and multifaceted coverage which assumingly leads to a loss of interest. In the German media, the human-being's own accountability, as well as responsibility, are underlined which is almost never questioned among the public (Engels, Hüther, Schäfer, \& Held, 2013; Peters \& Heinrichs, 2008). This may sensitize people and motivate them to act even though they believe they lack sufficient information on what action they can actually take to mitigate climate change. However, they lack references at the individual's level, and to their own world (Lörcher \& Taddicken, 2017). This corresponds with the finding that the media mostly reported climate science findings regarding appropriate political solutions (Schäfer, 2017).

Moreover, it underlines the findings of Olausson (2011), O'Neill and NicholsonCole (2009) and Lowe et al. (2006). In their studies on climate change, the participants also complained of a certain degree of top- 
ic and media fatigue. Rather than raising awareness of the problem, the intensity of the negatively perceived media coverage of climate change seems to lead to a certain level of frustration and a decrease in attention. The audience may distance and disengage from climate change (Lidskog et al., 2020). Thus, as Arlt et al. (2011) have shown, the media do not always have an awareness-heightening effect. Moreover, if the fear appeals within reporting do not actually occur, media and scientific authority may lose its credibility. Therefore, sensationalism and fear seem to be inappropriate tools for climate change communication.

In this study, a constructive reporting and more multifaceted coverage was said to enable the re-awakening of interest in climate change. This goes along with a shift in journalism toward what can be called either solution journalism (McIntyre, 2017) or constructive journalism (McIntyre \& Gyldensted, 2018). This style can be described as an "emerging form of journalism that involves applying positive techniques to news processes and production in an effort to create productive and engaging coverage, while holding true to journalism's core functions" (McIntyre \& Gyldensted, 2018, p. 22). This emerging journalism style has not yet been well-researched. In addition, framing analyses prove that the framing component of treatment recommendation (following Entman, 1993, p. 52) has yet to gain prominence in the media coverage of climate change (Brüggemann, Neverla, Hoppe, \& Walter, 2018; Hart, 2010; Schäfer \& O’Neill, 2017) - but is greatly desired by the audience as our findings show.

Perhaps equally important is the perception of an uncreative and uniform media coverage. A broader variety, considering the differences of media channels, could help to overcome the climate change fatigue expressed in the discussions and also meet the audiences' desire for high quality information which is, at the same time, not too extensive.

Furthermore, the use of humor has the potential to make science more appealing and assessable to the general au- dience (Pinto \& Riesch, 2017). The participants shared this idea and considered this kind of reporting style as a pleasant approach in contrast to the usually serious, unstimulating scientific information. This might stimulate attention and critical reflection. However, participants also expressed their concern that humor might trivialize the importance of issues such as climate change and overly simplifies science. These findings are in line with results of previous studies (Bore \& Reid, 2014; Riesch, 2015), but should be researched more deeply in the future.

How the media should handle the science-inherent uncertainty as well as the complex and abstract character of science issues such as climate change was discussed inconsistently as well. It became obvious that some participants did not feel comfortable with media content representing different science perspectives: They seemed to feel overwhelmed and at a loss when comprehending and assessing the scientific details. Similar statements were found among participants by Maier et al. (2016) on the issue of nanotechnology. Here, the participants desired reliable information, which enables them to make everyday decisions. They felt insecure and hoped for guidance from the media. Others found their expectations of scientifically accurate information on processes and different science perspectives fulfilled. So far, the perception and processing of scientific uncertainties in the media is not yet fully understood. It is assumed that individual predispositions are relevant here, such as uncertainty and ambiguity tolerance, need for cognition, attitudes toward science and the issue, as well as the individual's media usage of science-related content.

These findings not only reflect the assumption of the TSQA that the audience does not only consider the fulfillment of their own needs and demands when assessing media coverage, but evaluates specific characteristics and structures of media products (Wolling, 2009). The audience also takes into account the specifics of the topic being reported about. Their individual view on climate change and 
their knowledge and attitudes toward the issue have strongly influenced how they desired the topic to be presented in different genres and reporting styles. Moreover, their opinion on what tasks and functions the media should fulfill also played an important role. Both aspects have not yet been addressed in the theoretical framework of TSQA, but should be integrated as possible influencing factors on expectations. Although it is plausible to assume overarching quality dimensions, the expectations of how the media should report on a scientific issue - and thus how the dimensions should be put into practice may be to a certain extent individually dependent.

Further theoretical developments and investigations of the relation between expectations, assessments and media use can contribute to research about science communication which has only just begun to examine questions of quality. To date, no established definitions of characteristics and standards exist (Wormer, 2017). The proposed six quality dimensions in this study do not represent an exhaustive catalogue of criteria, but may serve as a starting point to systematically group characteristics by which the quality of science journalism can be described and assessed.

\section{Limitations and outlook}

In general, the audience perspective should be given more attention in future studies. This study contributes to this research gap, however, some limitations must be kept in mind.

First, while our study focused on the issue of climate change, we assume that our findings can be generalized well beyond. Nonetheless, future studies may continue working on quality expectations and expanding the questions asked here to other scientific issues or even the field of science in general.

Moreover, it would be interesting to explore the role of the Fridays for Future movement and its coverage in more detail. We found that it was important for the participants that the media cover activities at the individual's level, possibilities to engage and "do something". Participants also suggested presenting more role models. Greta Thunberg has certainly been one such role model, as well as other Fridays for Future activists (Bergmann \& Ossewaarde, 2020).

Although we used a pre-questionnaire to create heterogeneous groups, only individuals with at least a minimum-level of interest in climate change participated. Furthermore, as participants converse in groups, effects of social desirability are to be expected. Statements about the participants' strong interest in science, their willingness to combat climate change, and their critical perspective of the media could have been made partly due to the social situation.

Moreover, it is important to consider that the assessments and expectations of the media coverage's quality were partly initiated by three audiovisual stimuli. Unfortunately, it was not possible to explore how their stated expectations and assessments are related to their daily media usage behavior and how far their expectations can be traced back to this. As the interaction between expectations and assessments are not only mutual but also particularly iterative, a methodological approach to consider the dynamics of the process seems to be promising. Moreover, the actual media use and selection processes should be considered more intensively in future work using representative methods.

Furthermore, Wolling (2009, p. 98) states that, regarding the operationalization of the TSQA "[g]ranted, the conceptual development and theoretical hypotheses are by no means complete; neither are the means of getting empirical testing fully operational." We suppose that within a quantitative survey, both perceptions and assessments could be measured more differentiated than in qualitative studies, e.g., to let the participants agree with statements about the climate change coverage in order to measure their perceptions and to ask in a second step how well this is liked. This could contribute to a deep- 
er understanding of differentiated quality assessments. Moreover, different views and perceptions of climate change in the media have become obvious throughout the discussions. There were participants who argued clearly from a pro anthropogenic climate change stance and seemed well-informed, and others seemed to be more open to different perspectives and welcomed multifaceted media information. Thus, we believe developing an audience typology regarding different expectations and assessments of climate change in the media to be clearly helpful (Wicke \& Taddicken, 2020). Such a typology could not only improve goal-oriented communication or facilitate the tailoring of communication campaigns, but also help to better adapt the media content to the differing needs of the audience and thus prevent or eliminate media frustration with climate change.

One of the greatest challenges science journalism presently faces is how to reach a broad audience. Raising the understanding of how the media should report about scientific issues and research findings from the perspective of the audience may help to develop appropriate means and effective ways of reporting and therefore deserves further attention in future research.

\section{Acknowledgment}

The research presented in this paper was conducted as part of the project "Climate change from the audience perspective" which was part of the Special Priority Program 1409 "Science and the public", funded by the German Research Foundation (DFG).

\section{Conflict of interest}

The authors declare no conflict of interests.

\section{Data availability statement}

The original, unedited data that support the findings of this study are available from the corresponding author upon reasonable request.

\section{Supplementary material}

Supplementary material for this article is available online in the format provided by the authors (unedited). https:// www.hope.uzh.ch/scoms/article/view/j. scoms.2021.01.004

\section{References}

Albæk, E. (2011). The interaction between experts and journalists in news journalism. Journalism, 12(3), 335-348. https://doi. org/10.1177/1464884910392851

Arlt, D., Hoppe, I., \& Wolling, J. (2011). Climate change and media usage: Effects on problem awareness and behavioural intentions. International Communication Gazette, 73(1-2), 45-63. https://doi. org/10.1177/1748048510386741

Ashe, T. (2013). How the media report scientific risk and uncertainty: A review of the literature. Reuters Institute for the Study of Journalism. Retrieved from https:// reutersinstitute.politics.ox.ac.uk/sites/ default/files/2017-11/How\%20the\%20 Media\%20Report\%20Risk\%20and\%20Uncertainty_0.pdf.

Balmford, A., Manica, A., Airey, L., Birkin, L., Oliver, A., \& Schleicher, J. (2004). Hollywood, climate change, and the public. Science (New York, N.Y.), 305(5691), 1713. https:// doi.org/10.1126/science.305.5691.1713b

Barkemeyer, R., Figge, F., Hoepner, A., Holt, D., Kraak, J. M., \&Yu, P.-S. (2017). Media coverage of climate change: An international comparison. Environment and Planning C: Politics and Space, 35(6), 1029-1054. https://doi. org/10.1177/0263774X16680818

Beattie, G., Sale, L., \& Mcguire, L. (2011). An inconvenient truth? Can a film really affect psychological mood and our explicit attitudes towards climate change? Semi- 
otica, 2011(187), 105-125. https://doi. org/10.1515/semi.2011.066

Bergmann, Z., \& Ossewaarde, R. (2020). Youth climate activists meet environmental governance: ageist depictions of the FFF movement and Greta Thunberg in German newspaper coverage. Journal of Multicultural Discourses, 15(3), 267-290. https:// doi.org/10.1080/17447143.2020.1745211

Blumler, J. G. (1979). The role of theory in uses and gratifications studies. Communication Research, 6(1), 9-36. https://doi. org/10.1177/009365027900600102

Bolin, J. L., \& Hamilton, L. C. (2018). The news you choose: News media preferences amplify views on climate change. Environmental Politics, 27(3), 455-476. https:// doi.org/10.1080/09644016.2018.1423909

Bore, I.-L. K., \& Reid, G. (2014). Laughing in the face of climate change? Satire as a device for engaging audiences in public debate. Science Communication, 36(4), 454-478. https://doi. org/10.1177/1075547014534076

Brüggemann, M., \& Engesser, S. (2017). Beyond false balance: How interpretive journalism shapes media coverage of climate change. Global Environmental Change, 42, 58-67. https://doi.org/10.1016/j.gloenvcha.2016.11.004

Brüggemann, M., Neverla, I., Hoppe, I., \& Walter, S. (2018). Klimawandel in den Medien [Climate change in the media]. In H. von Storch, I. Meinke, \& M. Claussen (Eds.), Hamburger Klimabericht: Wissen über Klima, Klimawandel und Auswirkungen in Hamburg und Norddeutschland [Hamburg climate report: Knowledge about climate, climate change and effects in Hamburg and Northern Germany] (pp. 243-254). Berlin: Springer Spektrum. https://doi. org/10.1007/978-3-662-55379-4_12

Bullock, O. M., Colón Amill, D., Shulman, H. C., \& Dixon, G. N. (2019). Jargon as a barrier to effective science communication: Evidence from Metacognition. Public Understanding of Science, 28(7), 845-853. https://doi. org/10.1177/0963662519865687

Carmichael, J. T., Brulle, R. J., \& Huxster, J. K. (2017). The great divide: Understanding the role of media and other drivers of the partisan divide in public concern over climate change in the USA, 2001-2014. Climatic Change, 141(4), 599-612. https:// doi.org/10.1007/s10584-017-1908-1

Charmaz, K. (2014). Constructing grounded theory. Introducing qualitative methods. London: Sage.

Corner, A., Whitmarsh, L., \& Xenias, D. (2012). Uncertainty, scepticism and attitudes towards climate change: Biased assimilation and attitude polarisation. Climatic Change, 114(3-4), 463-478. https://doi. org/10.1007/s10584-012-0424-6

Cyr, J. (2016). The pitfalls and promise of focus groups as a data collection method. Sociological Methods \& Research, 45(2), 231-259. https://doi. org/10.1177/0049124115570065

Ding, D., Maibach, E. W., Zhao, X., RoserRenouf, C., \& Leiserowitz, A. (2011). Support for climate policy and societal action are linked to perceptions about scientific agreement. Nature Climate Change, 1(9), 462-466. https://doi.org/10.1038/nclimate1295

Donsbach, W., Rentsch, M., Schielicke, A. M., \& Degen, S. (2009). Entzauberung eines Berufs: Was die Deutschen vom Journalismus erwarten und wie sie enttäuscht werden [Demystification of a profession. What Germans expect from journalism and how it disappoints them]. Konstanz: UVK.

Dresing, T., \& Pehl, T. (Eds.). (2015). Manual (on) transcription: Transcription conventions, software guides and practical hints for qualitative researchers. Retrieved from https://www.audiotranskription. de/wp-content/uploads/2020/11/manual-on-transcription.pdf.

Dunwoody, S. (1999). Scientists, journalists, and the meaning of uncertainty. In S. M. Friedman, S. Dunwoody, \& C. L. Rogers (Eds.), Communicating uncertainty: Media coverage of new and controversial science (pp. 59-79). Mahwah, NJ: Erlbaum Associates.

Engels, A., Hüther, O., Schäfer, M., \& Held, H. (2013). Public climate-change skepticism, energy preferences and political participation. Global Environmental Change, 23(5), 1018-1027. https://doi.org/10.1016/j. gloenvcha.2013.05.008

Engesser, S., \& Brüggemann, M. (2016). Mapping the minds of the mediators: The 
cognitive frames of climate journalists from five countries. Public Understanding of Science, 25(7), 825-841. https://doi. org/10.1177/0963662515583621

Entman, R. M. (1993). Framing: Toward clarification of a fractured paradigm. Journal of Communication, 43(4), 51-58. https://doi. org/10.1111/j.1460-2466.1993.tb01304.x

Feldman, L., Hart, P. S., \& Milosevic, T. (2017). Polarizing news? Representations of threat and efficacy in leading US newspapers' coverage of climate change. Public Understanding of Science, 26(4), 481-497. https://doi. org/10.1177/0963662515595348

Guenther, L., Bischoff, J., Löwe, A., Marzinkowski, H., \& Voigt, M. (2017). Scientific evidence and science journalism. Journalism Studies, 20(1), 40-59. https://doi.org/10.10 80/1461670X.2017.1353432

Hart, P. S. (2010). One or many? The influence of episodic and thematic climate change frames on policy preferences and individual behavior change. Science Communication, 33(1), 28-51. https://doi. org/10.1177/1075547010366400

Hart, P. S., \& Feldman, L. (2014). Threat without efficacy? Climate change on U.S. network news. Science Communication, 36(3), 325-351. https://doi. org/10.1177/1075547013520239

Helfferich, C. (2011). Die Qualität qualitativer Daten: Manual für die Durchführung qualitativer Interviews [The quality of qualitative data: Manual for conducting qualitative interviews] (4th ed.). Wiesbaden: VS Verlag für Sozialwissenschaften. https:// doi.org/10.1007/978-3-531-92076-4

Howell, R. A. (2011). Lights, camera ... action? Altered attitudes and behaviour in response to the climate change film The Age of Stupid. Global Environmental Change, 21(1), 177-187. https://doi.org/10.1016/j. gloenvcha.2010.09.004

Hurst, S., Arulogun, O. S., Owolabi, A. O., Akinyemi, R., Uvere, E., Warth, S., \& Ovbiagele, B. (2015). Pretesting qualitative data collection procedures to facilitate methodological adherence and team building in Nigeria. International Journal of Qualitative Methods, 14, 53-64. https:// doi.org/10.1177/160940691501400106
Jensen, J. D. (2008). Scientific uncertainty in news coverage of cancer research: Effects of hedging on scientists and journalists credibility. Human Communication Research, 34(3), 347-369. https://doi. org/10.1111/j.1468-2958.2008.00324.x

Johnson, B. B. (2003). Further notes on public response to uncertainty in risks and science. Risk Analysis, 23(4), 781-789. https:// doi.org/10.1111/1539-6924.00355

Kaiser, J., \& Rhomberg, M. (2016). Questioning the doubt: Climate skepticism in German newspaper reporting on COP17. Environmental Communication, 10(5), 556-574. https://doi.org/10.1080/17524032.2015.1 050435

Kirilenko, A. P., \& Stepchenkova, S. O. (2012). Climate change discourse in mass media: Application of computer-assisted content analysis. Journal of Environmental Studies and Sciences, 2(2), 178-191. https://doi. org/10.1007/s13412-012-0074-z

Kuckartz, U. (2018). Qualitative Inhaltsanalyse. Methoden, Praxis, Computerunterstützung [Qualitative content analysis. Methods, practice, computer support]. Weinheim: Beltz Juventa.

Kühn, T., \& Koschel, K.-V. (2011). Gruppendiskussionen: Ein Praxis-Handbuch [Group discussions. A practice manual]. Wiesbaden: VS Verlag für Sozialwissenschaften.

Lidskog, R., Berg, M., Gustafsson, K. M., \& Löfmarck, E. (2020). Cold science meets hot weather: Environmental threats, emotional messages and scientific storytelling. Media and Communication, 8(1), 118-128. https://doi.org/10.17645/mac.v8i1.2432

Lindlof, T. R., \& Taylor, B. C. (2019). Qualitative communication research methods ( $4^{\text {th }} \mathrm{ed}$.). Los Angeles, CA: Sage.

Loosen, W., \& Schmidt, J.-H. (2012). (Re-) Discovering the audience. Information, Communication \& Society, 15(6), 867-887. https://doi.org/10.1080/136911 8X.2012.665467

Lörcher, I., \& Taddicken, M. (2017). Discussing climate change online. Topics and perceptions in online climate change communication in different online public arenas. Journal of Science Communication, 16(02). https://doi.org/10.22323/2.16020203

Lowe, T., Brown, K., Dessai, S., França Doria, M. de, Haynes, K., \& Vincent, K. (2006). 
Does tomorrow ever come? Disaster narrative and public perceptions of climate change. Public Understanding of Science, 15(4), 435-457. https://doi. org/10.1177/0963662506063796

Maier, M., Milde, J., Post, S., Günther, L., Ruhrmann, G., \& Barkela, B. (2016). Communicating scientific evidence: Scientists', journalists' and audiences' expectations and evaluations regarding the representation of scientific uncertainty. Communications, 41(3), 239-264. https://doi.org/10.1515/ commun-2016-0010

Mason, M. (2010). Sample size and saturation in PhD studies using qualitative interviews. Forum Qualitative Sozialforschung / Forum: Qualitative Social Research, 11(3), Art. 8. https://doi.org/10.17169/fqs11.3 .1428

Maurer, M. (2011). Wie Journalisten mit Ungewissheit umgehen. Eine Untersuchung am Beispiel der Berichterstattung über die Folgen des Klimawandels [How journalists deal with uncertainty. An investigation using the example of the media coverage of the consequences of climate change]. Medien \& Kommunikationswissenschaft, 59(1), 60-74. https://doi. org/10.5771/1615-634x-2011-1-60

Mayring, P. (2014). Qualitative content analysis: Theoretical foundation, basic procedures and software solution. Retrieved from https://nbn-resolving.org/ urn:nbn:de:0168-ssoar-395173

Mayring, P., \& Fenzl, T. (2019). Qualitative Inhaltsanalyse [Qualitative content analysis]. In N. Baur \& J. Blasius (Eds.), Handbuch Methoden der empirischen Sozialforschung [Handbook methods of empirical social research] (pp. 633-648). Wiesbaden: Springer Fachmedien. https://doi.org/10.1007/9783-658-21308-4_42

McIntyre, K. (2017). Solutions journalism. Journalism Practice, 13(1), 16-34. https://doi. org/10.1080/17512786.2017.1409647

McIntyre, K., \& Gyldensted, C. (2018). Constructive journalism. An introduction and practical guide for applying positive psychology techniques to news production. The Journal of Media Innovations, 4(2), 20-34. https://doi.org/10.5617/jomi. v4i2.2403
Metag, J., Füchslin, T., \& Schäfer, M. S. (2015). Global warming's five Germanys: A typology of Germans' views on climate change and patterns of media use and information. Public Understanding of Science, 26(4), 434-451. https://doi. org/10.1177/0963662515592558

Metag, J., Schäfer, M. S., Füchslin, T., Barsuhn, T., \& Kleinen-von Königslöw, K. (2016). Perceptions of climate change imagery. Science Communication, 38(2), 197-227. https://doi. org/10.1177/1075547016635181

Milde, J., \& Barkela, B. (2016). Wie Rezipienten mit wissenschaftlicher Ungesichertheit umgehen: Erwartungen und Bewertungen bei der Rezeption von Nanotechnologie im Fernsehen [How recipients deal with scientific uncertainty: expectations and evaluations in the reception of nanotechnology on television]. In G. Ruhrmann, L. Guenther, \& S. H. Kessler (Eds.), Wissenschaftskommunikation zwischen Risiko und (Un-)Sicherheit [Science communication between risk and (un)certainty] (pp. 193-211). Köln: Herbert von Halem.

Morgan, D. L. (1997). Focus groups as qualitative research. Thousand Oaks, CA: Sage. https://doi.org/10.4135/9781412984287

Morton, T. A., Rabinovich, A., Marshall, D., \& Bretschneider, P. (2011). The future that may (or may not) come: How framing changes responses to uncertainty in climate change communications. Global Environmental Change, 21(1), 103-109. https://doi.org/10.1016/j.gloenvcha.2010.09.013

Moser, A., \& Korstjens, I. (2018). Series: Practical guidance to qualitative research. Part 3: Sampling, data collection and analysis. The European Journal of General Practice, 24(1), 9-18. https://doi.org/10.1080/13814 788.2017.1375091

National Science Board. (2018). Science and Engineering Indicators 2018. Retrieved from https://www.nsf.gov/statistics/indicators.

Nelson, J. (2017). Using conceptual depth criteria: addressing the challenge of reaching saturation in qualitative research. Qualitative Research, 17(5), 554-570. https://doi. org/10.1177/1468794116679873

Newman, N., \& Fletcher, R. (2017). Bias, bullshit and lies: Audience perspectives on low 
trust in the media. Retrieved from https:// reutersinstitute.politics.ox.ac.uk/our-research/bias-bullshit-and-lies-audienceperspectives-low-trust-media.

Newman, T. P., Nisbet, E. C., \& Nisbet, M. C. (2018). Climate change, cultural cognition, and media effects: Worldviews drive news selectivity, biased processing, and polarized attitudes. Public Understanding of Science, 27(8), 985-1002. https://doi. org/10.1177/0963662518801170

Nisbet, M. C., Ho, S., Markowitz, E., O’Neill, S. J., Schäfer, M. S., \& Thaker, J. (Eds.). (2017). Oxford encyclopedia of climate change communication. Oxford: Oxford University Press.

Nolan, J. M. (2010). "An Inconvenient Truth" increases knowledge, concern, and willingness to reduce greenhouse gases. Environment and $\mathrm{Be}$ havior, 42(5), 643-658. https://doi. org/10.1177/0013916509357696

O'Neill, S. (2013). Image matters: Climate change imagery in US, UK and Australian newspapers. Geoforum, 49, 10-19. https:// doi.org/10.1016/j.geoforum.2013.04.030

O'Neill, S., \& Nicholson-Cole, S. (2009). "Fear Won't Do It". Science Communication, 30(3), 355-379. https://doi. org/10.1177/1075547008329201

O’Neill, S., Williams, H. T. P., Kurz, T., Wiersma, B., \& Boykoff, M. (2015). Dominant frames in legacy and social media coverage of the IPCC Fifth Assessment Report. Nature Climate Change, 5(4), 380-385. https:// doi.org/10.1038/nclimate2535

O’Reilly, M., \& Parker, N. (2013). “Unsatisfactory Saturation": a critical exploration of the notion of saturated sample sizes in qualitative research. Qualitative Research, 13(2), 190-197. https://doi. org/10.1177/1468794112446106

Olausson, U. (2009). Global warming global responsibility? Media frames of collective action and scientific certainty. Public Understanding of Science, 18(4), 421-436. https://doi. org/10.1177/0963662507081242

Olausson, U. (2011). "We're the Ones to Blame": Citizens' representations of climate change and the role of the media. Environmental Communication, 5(3), 281-299. https://doi.org/10.1080/17524032.2011.5 85026

Painter, J. (2014). Disaster Averted? Television Coverage of the 2013/14 IPCC's Climate Change Reports. Retrieved from https:// ora.ox.ac.uk/objects/uuid:1a34998e-407b4c06-a9df-9d8a934ca249

Peters, H. P., \& Heinrichs, H. (2008). Legitimizing climate policy: The "risk construct" of global climate change in the German mass media. International Journal of Sustainability Communication. Retrieved from http://www.hpp-online.de/downloads/peters_\&_heinrichs_2008.pdf.

Pinto, B., \& Riesch, H. (2017). Are audiences receptive to humour in popular science articles? An exploratory study using articles on environmental issues. Journal of Science Communication, 16(04). https:// doi.org/10.22323/2.16040201

Rabinovich, A., \& Morton, T. A. (2012). Unquestioned answers or unanswered questions: Beliefs about science guide responses to uncertainty in climate change risk communication. Risk Analysis, 32(6), 992-1002. https://doi.org/10.1111/j.15396924.2012.01771.x

Retzbach, A., \& Maier, M. (2015). Communicating scientific uncertainty: Media effects on public engagement with science. Communication Research, 42(3), 429-456. https:// doi.org/10.1177/0093650214534967

Riesch, H. (2015). Why did the proton cross the road? Humour and science communication. Public Understanding of Science, 24(7), 768-775. https://doi. org/10.1177/0963662514546299

Ryghaug, M., Sørensen, K. H., \& Naess, R. (2010). Making sense of global warming: Norwegians appropriating knowledge of anthropogenic climate change. Public Understanding of Science, 20(6), 778-795. https://doi. org/10.1177/0963662510362657

Saunders, B., Sim, J., Kingstone, T., Baker, S., Waterfield, J., Bartlam, B., Burroughs, H., \& Jinks, C. (2018). Saturation in qualitative research: Exploring its conceptualization and operationalization. Quality \& Quantity, 52(4), 1893-1907. https://doi. org/10.1007/s11135-017-0574-8

Schäfer, M. S. (2017). Climate change communication in Germany. In M. C. Nis- 
bet, S. Ho, E. Markowitz, S. J. O'Neill, M. S. Schäfer, \& J. Thaker (Eds.), Oxford encyclopedia of climate change communication. Oxford: Oxford University Press. https://doi.org/10.1093/acrefore/9780190228620.013.448

Schäfer, M. S., \& O’Neill, S. J. (2017). Frame analysis in climate change communication: Approaches for assessing journalists' minds, online communication and media portrayals. In M. C. Nisbet, S. Ho, E. Markowitz, S. J. O’Neill, M. S. Schäfer, \& J. Thaker (Eds.), Oxford encyclopedia of climate change communication. Oxford: Oxford University Press. https://doi.org/10.1093/acrefore/9780190228620.013.487

Schmidt, A., Ivanova, A., \& Schäfer, M. S. (2013). Media attention for climate change around the world: A comparative analysis of newspaper coverage in 27 countries. Global Environmental Change, 23(5), 1233-1248. https://doi.org/10.1016/j. gloenvcha.2013.07.020

Sommer, M., Rucht, D., Haunss, S., \& Zajak, S. (2019). Fridays for Future. Profil, Entstehung und Perspektiven der Protestbewegung in Deutschland [Fridays for Future. Profile, emergence and perspectives of the protest movement in Germany]. Berlin: Institut für Protest- und Bewegungsforschung. https://doi.org/10.17169/REFUBIUM-4088

Stocking, S. H., \& Holstein, L. W. (2009). Manufacturing doubt: Journalists' roles and the construction of ignorance in a scientific controversy. Public Understanding of Science, 18(1), 23-42. https://doi. org/10.1177/0963662507079373

Su, L. Y.-F., Akin, H., Brossard, D., Scheufele, D. A., \& Xenos, M. A. (2015). Science news consumption patterns and their implications for public understanding of science. Journalism \& Mass Communication Quarterly, 92(3), 597-616. https://doi. org/10.1177/1077699015586415

Summ, A., \& Volpers, A.-M. (2016). What's science? Where's science? Science journalism in German print media. Public Understanding of Science, 25(7), 775-790. https://doi. org/10.1177/0963662515583419
Taddicken, M. (2013). Climate change from the user's perspective. Journal of Media Psychology, 25(1), 39-52. https://doi. org/10.1027/1864-1105/a000080

Visschers, V. H. M. (2018). Public perception of uncertainties within climate change science. Risk Analysis, 38(1), 43-55. https:// doi.org/10.1111/risa.12818

Vogl, S. (2019). Gruppendiskussion [Group discussion]. In N. Baur \& J. Blasius (Eds.), Handbuch Methoden der empirischen Sozialforschung [Handbook methods of empirical social research] (pp. 695-700). Wiesbaden: Springer Fachmedien. https:// doi.org/10.1007/978-3-658-21308-4_46

Vorderer, P. (1992). Fernsehen als Handlung: Fernsehfilmrezeption aus motivationspsychologischer Perspektive [Television as action: television film reception from a motivational psychology perspective]. Berlin: Ed. Sigma.

Vowe, G., \& Wolling, J. (2004). Radioqualität: Was die Hörer wollen und was die Sender bieten: vergleichende Untersuchung zu Qualitätsmerkmalen und Qualitätsbewertungen von Radioprogrammen in Thüringen, Sachsen-Anhalt und Hessen [Radio quality - what listeners want and what broadcasters offer. A comparative investigation of the characteristics and evaluations of the quality of radio programs in Thuringia, Saxony-Anhalt, and Hesse]. München: Kopaed.

Weingart, P., Engels, A., \& Pansegrau, P. (2000). Risks of communication: Discourses on climate change in science, politics, and the mass media. Public Understanding of Science, 9(3), 261-283. https://doi. org/10.1088/0963-6625/9/3/304

Wicke, N., \& Taddicken, M. (2020). Listen to the audience(s)! Expectations and characteristics of expert debate attendants. Journal of Science Communication, 19(04), A02. https://doi.org/10.22323/2.19040202

Wiedemann, P. M., \& Schütz, H. (2008). The role of evidence in risk characterization: Making sense of conflicting data. Weinheim: Wiley-VCH-Verl.

Wissenschaft im Dialog. (2018). Wissenschaftsbarometer 2018 [Science Barometer 2018]. Retrieved from https://www.wissenschaft-im-dialog.de/fileadmin/user_upload/Projekte/Wissenschaftsbarometer/ 
Dokumente_18/Downloads_allgemein/ Sciencebarometer2018_Brochure_web. pdf.

Wissenschaft im Dialog. (2020). Wissenschaftsbarometer 2020 [Science Barometer 2020]. Retrieved from https://www.wissenschaft-im-dialog.de/fileadmin/user_upload/Projekte/Wissenschaftsbarometer/ Bilder/Wissenschaftsbarometer_2020/ English/2020_WiBa_EN_Brochure.pdf.

Wolling, J. (2004). Qualitätserwartungen, Qualitätswahrnehmungen und die Nutzung von Fernsehserien [Quality expectations, quality perceptions, and the use of television series]. Publizistik, 49(2), 171-193. https:// doi.org/10.1007/s11616-004-0035-y
Wolling, J. (2009). The effect of subjective quality assessments on media selection. In T. Hartmann (Ed.), Media choice: A theoretical and empirical overview (pp. 84-101). New York, NY: Routledge.

Wormer, H. (2017). Vom Public Understanding of Science zum Public Understanding of Journalism [From a public understanding of science to a public understanding of journalism]. In H. Bonfadelli, B. Fähnrich, C. Lüthje, J. Milde, M. Rhomberg, \& M. S. Schäfer (Eds.), Forschungsfeld Wissenschaftskommunikation [The research field of science communication] (pp. 429-451). Wiesbaden: Springer Fachmedien. https:// doi.org/10.1007/978-3-658-12898-2_23 